\title{
La investigación en artes en Colombia: como la aprendimos, como la hacemos y como la enseñamos
}

\section{Research in arts in Colombia: how we learned it, how we do it and how we teach it}

TIPO DE TRABAJO: Comunicación virtual.

PALABRAS CLAVE

Investigación Artística, Investigación-Creación, Artes Visuales, Enseñanza de las Artes.

KEY WORDS

Artistic Research, Investigation-Creation, Visual Arts, Arts Education.

RESUMEN

Esta comunicación tiene por propósito exponer tres momentos relacionados con nuestras experiencias y reflexiones en torno a la investigación en artes en el contexto colombiano. El primer momento tiene relación con unos aprendizajes teóricos derivados de las lecturas de artículos y libros, las discusiones con expertos y la participación en encuentros académicos. En lo que respecta al segundo momento el centro de la discusión surge de nuestra propia práctica artística desarrollada como investigación en el marco de los estudios de maestría y doctorado. Y el tercer momento se remite a la práctica docente en el área de las artes visuales, en donde hemos tenido que impartir clases en pregrado y posgrado, y coordinar distintos niveles de proyectos de investigación artística, o investigación-creación como se le conoce en Colombia. En tal sentido, el enfoque de esta propuesta se sustenta desde una reflexión teórica apoyada en un estudio de casos en conexión con los momentos arriba mencionados. En el primer momento, se rastrearán unos autores clave a nivel nacional e internacional que caracterizan el concepto de investigación en artes según sus intereses; en el segundo momento, se desplegarán nuestras investigaciones artísticas personales en donde hacen eco estos autores y nuestras intuiciones como creadores/profesores/investigadores; y en el tercer momento, se seleccionarán algunos proyectos de investigación en artes de los estudiantes que ejemplifican las potencias y dificultades de la implementación de unos discursos internacionales en un contextos localizados en Colombia. Dar cuenta de estas particularidades y confrontarlas con la discusión actual que plantea el IV Congreso Internacional en Investigación en Artes Visuales, permite una ampliación tanto del acto pedagógico como artístico en miras de la elaboración de un balance teórico-práctico que deberá revertir en nuevos rutas de enseñanza-aprendizaje de la investigación en artes.

\section{ABSTRACT}

The purpose of this presentation is to show three moments related to our experiences and thoughts around art research within the Colombian context. The first moment is related to some theoretical learning derived from the reading process of articles and books, the discussions with experts and the participation in academic meetings. Regarding the second moment, the center of the discussion arises from our own artistic practice developed as a research within our Master's and PhD studies. The third moment refers to the teaching practice in the visual arts area in which we have had to teach undergraduate and graduate classes, as well as coordinate different levels of research projects in the artistic research or research - creation categories, as it is known in Colombia. In that sense, the focus of this proposal is based on a theoretical reflection supported by a case study in connection with the moments mentioned above. In the first moment, some key authors will be traced at a national and international level that characterize the concept of art research according to their interests; for the second moment, our personal artistic research will be deployed where those authors echo and our intuitions as creators / professors / researchers; and in the third moment, some art research projects from students will be selected to exemplify the possibilities and difficulties of the implementation of international discourses in localized Colombian contexts. To give an account of these particularities and to confront them with the current discussion that the IV International 
Congress in Research in Visual Arts proposes, allows an extension of both the pedagogical and artistic act in view of the elaboration of a theoretical-practical balance that will have to revert in new routes of teaching-learning of arts research

\section{INTRODUCCIÓN}

Hablar de investigación-creación en Colombia supone encarar el panorama académico en el que ha emergido el concepto. Esta discusión que ha ganado cerca de dos décadas en el contexto universitario (principalmente en el entorno de las universidades públicas) adquirió legitimidad en el año 2015 cuando Colciencias, la entidad rectora de la investigación en el país, hizo visible el debate a través del documento "Modelo de medición de grupos de investigación, desarrollo tecnológico o innovación y de reconocimiento de investigadores del sistema nacional de ciencia, tecnología e innovación, año 2015". Proponer una definición de investigación-creación, concentró parte de los esfuerzos de los creadores/profesores/ investigadores a lo largo de este tiempo, por tal razón, resulta valioso aproximarla a este texto:

[La investigación- creación es] la indagación que busca responder a una pregunta o problema de investigación a través de una experiencia creativa que da lugar a obras, objetos o productos con valor estético y cuya naturaleza temporal puede ser efímera, procesual o permanente. En otras acepciones se considera que la investigación-creación - también llamada investigación artística, o investigación basada en la práctica - es aquella indagación que toma como objeto a la experiencia estética del propio investigador-creador, por lo cual siempre tiene un componente autorreflexivo (Borgdorff 2006; Asprilla 2013; Hernández Salgar 2014). Este énfasis en la experiencia, así como el carácter dinámico y relacional de la obra, hacen que la investigación-creación presente diferencias a nivel epistemológico, metodológico y ontológico con la investigación científica (Hannula er al. 2005; Borgdorff 2006). La investigación-creación conduce, por lo general a dos tipos de productos, la obra, objeto o producto de creación propiamente dicha y un texto en el cual se consigna la reflexión sobre la experiencia creativa y su relación con la pregunta o problema de investigación (Archer 1995; López-Cano 2013). (Colciencias, 2015, p. 33)

Para producir esta definición fue necesario cuestionar caminos epistemológicos opuestos a la creación como aquellos que valoran el método y la razón como el único horizonte para llegar al conocimiento (Grisales, 2012; Bambula, 2014); también significó acudir a discusiones provenientes de otros contextos geográficos donde el arte, la ciencia y la técnica coexisten como repertorios de saber capaces de producir cooperaciones y sinergias intelectivas sin perder su identidad epistemológica (Tornero, 2013; Hernández, 2006; Roldán, J. y Marín, R., 2012;), pero además, significó entender que la investigación-creación como puesta en forma (discursiva, estética y creativa) del conocimiento, conduce a una deliberación crítica sobre la relación que establecen los sujetos con sus saberes y los saberes de los otros (Asprilla, 2013; Silva, 2016; Borgdorff, 2006).

\section{METOdOLOGÍA}

Esta comunicación es el resultado de revisar unos logros en la práctica investigativa artística a la luz de autores y casos mundiales, así como, confrontar ese hacer con el discurso compartido en las aulas con estudiantes de pregrado y maestría. Las preguntas que han surgido siendo directores de proyectos de investigación en artes, resuenan aquí como respuestas y apuestas a futuro. Siendo coherentes con el campo que nos convoca hoy, este escrito solo ha sido posible gracias a un proceso de investigación basado en el hacer de la investigación en artes y en unas reflexiones docentes, haciendo docencia.

\section{DESARROLLO}

\section{1. ¿Cómo la aprendimos?}

Existen algunos libros que rastrean de forma muy acertada los distintos orígenes y caminos que ha tenido el concepto general de Investigación Artística, o el de Investigación en Artes, siendo el más reciente el del Profesor Lituano, Vytautas Michelkevicius (2018), quien propusiera un mapeo diagramático de las concepciones de la Investigación Artística, su estado en los programas doctorales, y en especial, su campo más cercano, el del arte contemporáneo en Lituania. Aquí resumiremos el propio camino recorrido, que en momentos coincide con el diagramado por el autor antes mencionado y que condensaremos a la luz del corto tiempo disponible en este espacio.

El campo de la Investigación en Artes, que aprendimos tiene principalmente cuatro fuentes: una norteamericana, trazada por el profesor Graeme Sullivan (2005), quien propone que la práctica artística puede llegar a considerarse como proceso de investigación; otra fuente que viene desde las discusiones planteadas por Henk Borgdorrff (2004), a su vez seguida por otros teóricos y practicantes del medio, hoy reunidos en la SAR (Society of Artistic Research); una tercera línea dictada desde los países nórdicos, principalmente Finlandia, con Hannula, Souranta y Vadén (2005; 2014), quienes conectan la discusión por la investigación en artes con su capacidad 
para el empoderamiento y la imaginación social; y una última, la construida por Fernando Hernández Hernández (2006) y otros teóricos españoles, en relación cercana al terreno de la investigación en educación artística.

\section{2. ¿Cómo la hacemos?}

En aras de darle sustrato reflexivo a nuestra propia práctica artística como profesores/creadores/investigadores, proponemos la extrapolación, al ámbito de la reflexión y el pensamiento estético-artístico materializados en el libro de artista, de cuatro (de seis) principios del rizoma, concepto expuesto por Deleuze y Guattari (2004[1988]).

Tanto la profesora Sandra Johana Silva Cañaveral como el profesor Álvaro Ricardo Herrera Zárate, decidieron -durante su formación posgradual- realizar un libro de artista o una libreta de pensamiento y producción estético-artístico con el objeto de sistematizar la experiencia de enseñanza-aprendizaje. Crear un libro de artista que sirvió como estrategia para no permanecer perdidos dentro del caos de la creación y de la reflexión, en tanto se pasa por etapas de intuición, especulación, incubación, incertidumbre y acomodo teórico, conceptual y creativo, tuvo por propósito sentar una discusión más profunda relativa a la manera como investigan los creadores y sistematizan el conocimiento sensible.
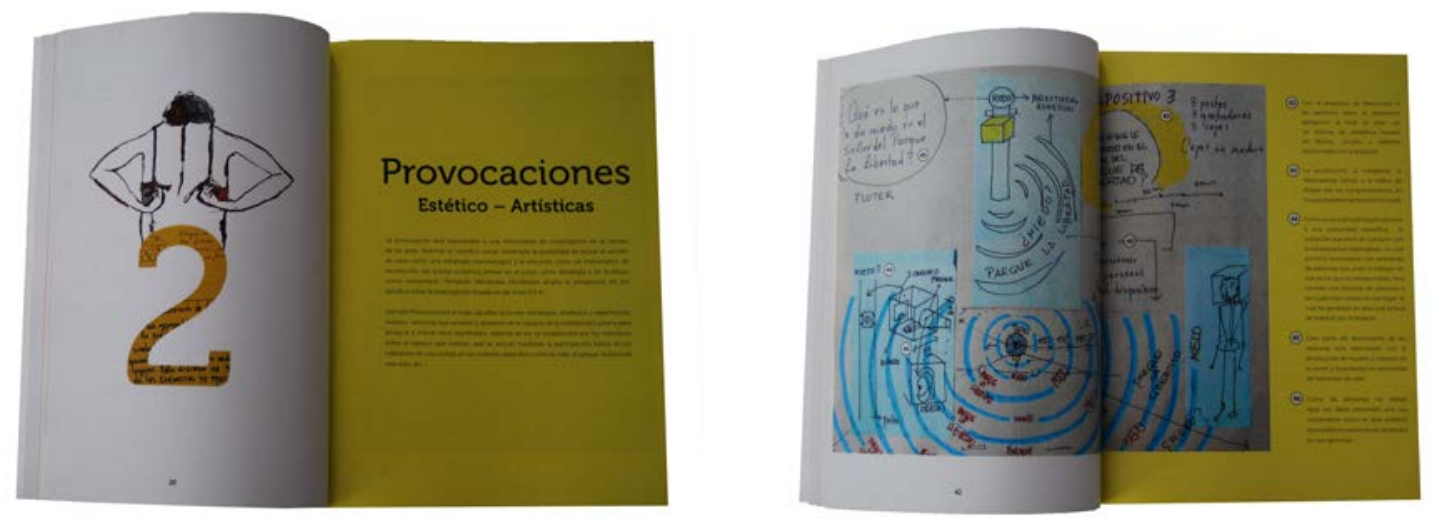

Figura 1. Sandra Johana Silva Cañaveral, 2016, libro de artista derivado de la tesis doctoral "Vestidos Orales y la visibilización de las identidades transgénero en el arte. Una reflexión en torno a la relación entre creación e investigación" (Fotografía de algunas páginas del libro).

El libro actúa como raíz de un árbol, es decir, como imagen del mundo, y el sujeto y el objeto ${ }^{1}$ como tubérculos, ramas o multiplicadores de esa imagen. Dicho en otras palabras, un libro es un cuerpo intermedio entre el sujeto y el objeto, hecho de las impresiones sensibles de cada uno, o sea, de las imágenes que pasan y son transformados por ellos. A este sistema de raíces, ramas y multiplicaciones es a lo que Deleuze y Guattari (2004[1988]) han llamado rizoma: "Un rizoma como tallo subterráneo se distingue radicalmente de las raíces y de las raicilla. Los bulbos, los tubérculos, son rizomas" (pp. 9-10).

Deleuze y Guattari describen seis principios que le son inherentes a ese sistema rizomático, de los cuales se extrapolan cuatro que le son correlativos a la investigación-creación: 1o conexión, 2을eterogeneidad, 3omultiplicidad y 4으 ruptura asignificante.

Con 1 o conexión, Deleuze y Guattari se refieren a modos de agenciar orden, inicialmente orden individual que podrá volverse orden colectivo y universal. Y con 20 heterogeneidad, a la capacidad de aglutinar actos diversos, "lingüísticos, pero también perceptivos, mímicos, gestuales, cogitativos" (2004 [1988], p. 13).

A pesar de todo lo que pueda decirse acerca de las formas de producción de conocimiento en la investigación académica y de todas las perspectivas desde las cuales puedan abordarse los conceptos, los materiales y los recursos técnicos en un proceso creativo, el libro de artista se constituye en un sistema propio de producción y presentación del conocimiento. Una forma particular y heterogénea que podrá conectarse con otras experiencias académicas, o incluso, con los acercamientos temáticos y las resoluciones plásticas y visuales de otros creadores. En todo caso, una manera de fijar orden que podrá convertirse en un orden útil para otros creadores.

\footnotetext{
1 Cabe mencionar que los "objetos" se están entendiendo en dos sentidos: como realidades y como subjetividades, así que el encuentro entre sujetos y objetos no es más que entre subjetividades y realidades.
} 
Ahora bien, en tanto rizoma la investigación-creación no da cuenta del conocimiento fragmentado en partes, lo hace aparecer en conjunto, lo muestra combinado y transformado por los sujetos y los objetos que intervienen como hacedores del conocimiento. Como hacer visible el tejido es su principal objetivo, evidenciar su capacidad para ondular en otros terrenos cognitivos y en sus cúmulos de saber es lo que le permite demostrar que es un método que no cesa de conectarse con otros saberes y otros sujetos. $\mathrm{A}$ esto Deleuze y Guattari llaman 3o la multiplicidad. De allí que se sugiera que la investigación-creación es un método genealógico: siempre está buscando hundir su raíz y el modo de conectar todas las ramas a la raíz del árbol. Por eso valora los registros de conocimiento legítimo y no legítimo, y a su vez los impugna para hacer surgir nuevos árboles (nuevos saberes) que sirvan de raíz a otras ramas (sujetos y objetos de conocimiento).
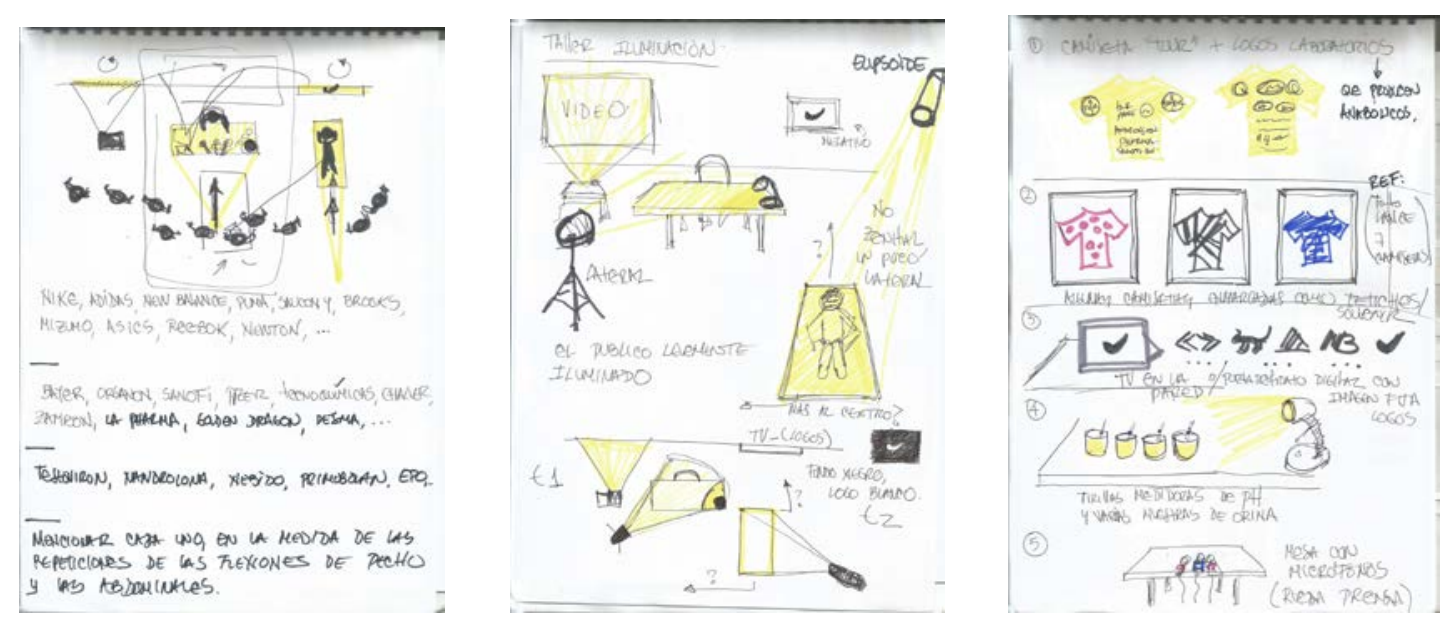

Figura 2. Álvaro Ricardo Herrera Zárate, 2013, libreta de artista derivada de la tesis de maestría “Cruzando la línea” (Fotografía de algunas páginas de la libreta).

Afirman los autores mencionados que el rizoma en tanto multiplicidad "se [define] por el afuera: por la línea abstracta, línea de fuga o de desterritorialización según la cual cambian de naturaleza al conectarse con otros" (2004 [1988], p. 14). Esto significa que la investigación-creación es un sistema compuesto por espacios legítimos y no legítimos del saber, territoriales y no territoriales, capaz de propiciar conexiones y 40 rupturas entre sujetos y objetos, así como dejar fugar ideas a otras esferas del conocimiento, que extrapola una vez se han transformado y con las cuales da nuevos significados al tejido. Por lo tanto, la distribución de la multiplicidad acaece en el libro de artista, pero también, en el soporte de escritura académica, en la obra y en los acontecimientos ocurridos en espacios académicos y no académicos del saber.

El libro de artista permitió mostrar cómo se construyen relaciones con otros sujetos y sus saberes, cómo hacen presencia los cuerpos y sus impresiones sensibles. El libro, en tanto imagen y lugar de convergencia del sujeto y el objeto, ofrece una conexión entre el saber académico y el saber sensible de la práctica artística. En suma, fue a través del libro de artista que el rizoma emergió como columna vertebral de un sistema de investigación-creación propio.

\section{3. ¿Cómo la enseñamos?}

Enseñar a hacer investigación en artes resulta inseparable de los dos puntos anteriormente mencionados: el de aprenderla desde unos teóricos y el de hacerla uno mismo en su práctica profesional. Algunas de las dificultades detectadas en el proceso de enseñanzaaprendizaje con los nuevos artistas es su dificultad para escribir sus documentos complementarios, y es allí, donde consideramos que los docentes deben encontrar formas muy particulares de motivar las escrituras pensando en un amplio abanico de posibilidades, que si bien, pueden estar cercanas al rigor de los textos científicos, deben abrirse a la multiplicidad de las escrituras creativas (cuento, narración, auto etnografías, o poesía), pero sobre todo, a la combinación con formatos más visuales, como el cómic, la novela gráfica, el fanzine o el foto ensayo, entre otros.

Para motivar estas texturas escriturales diversas resulta muy importante el estudio de casos, de los cuales queremos incluir solo un ejemplo en relación justamente con el formato cómic. En este campo resulta fundamental el ejemplo de Nick Sousanis (2015), quien para su tesis doctoral en la Universidad de Columbia, en el área de Educación en Estudios Interdisciplinares, desarrolló su disertación completamente en formato de cómic. Este ha sido un ejemplo que hemos usado tanto en maestría como en pregrado, seguido por algunos estudiantes que han visto grandes opciones para expresar sus indagaciones sin caer abrumados por una escritura totalmente textual. 

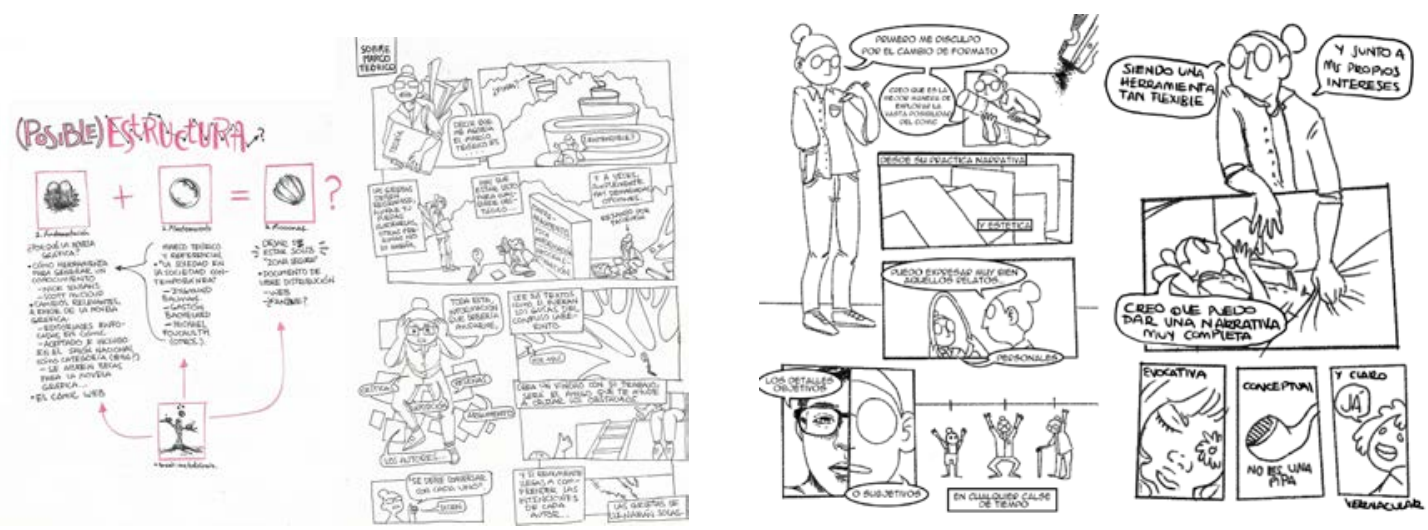

Figura 3. Ángela María Quintero Ojeda, 2019, avances del proyecto de Trabajo de Grado “Zona Segura” (Cómic).

Otra dificultad que se conecta con lo anterior es la complejidad que tiene el transportar los discursos de la investigación artística, que se han establecido sobre todo a nivel doctoral, hacia su aplicación en el primer ciclo de formación. La dificultad aquí radica en la profundidad teórica con la que son expresados estos discursos, y por otra parte, que en ellos se asume una destreza en la práctica que permite al creador investigador, hacerse preguntas válidas y no obvias sobre su propia práctica. En el pregrado, aún no se domina una práctica en específica y la densidad teórica es también incipiente. El reto está en dirigir las intenciones e inquietudes iniciales del estudiante, hacia algo que pueda ser rigurosamente descrito, documentado y evidenciado a la par que aprende esa práctica.

\section{CONCLUSIONES}

Los sujetos y los objetos son multiplicadores y multiplicidades simultáneamente: son afectados por otros rizomas, están enraizados en otros cuerpos, otras imágenes y otros mundos (los míos, los de mi congénere y los que inventamos juntos) y a la vez, pretenden enraizarse en otros cuerpos, transformarlos y producir nuevas imágenes y nuevos mundos. Exponer las estrategias con las cuales los creadores/profesores/investigadores alcanzamos resultados poéticos, metafóricos, críticos, estéticos, visuales y teóricos hace parte de esa correspondencia entre ser multiplicadores y multiplicidades. Solo de esta manera aportamos a la existencia de una comunidad de la práctica que se autorreflexiona y valora los registros de saber provenientes de múltiples lugares y sujetos. Por tal razón, resulta revelador que el acto pedagógico y el acto creativo, como modos particulares de interiorización y exteriorización de eso sensible que hay en el mundo y que se hace cognoscible a través de las imágenes, configure esta interconexión entre sujetos y realidades.

Consideramos que los valores a motivar en la investigación en artes están en el campo de la reflexión crítica y la experimentación constante de un hacer particular. Darle valor cognitivo a la creación significa entender que nuestros haceres son parte esencial de nuestros saberes y sentires. Solo con estudiantes valientes, que reten los formatos con su propio ejercicio artístico, puede ir desplazándose la frontera de los protocolos tradicionales de investigación, permitiendo que las universidades y sus departamentos, entiendan en toda su dimensión la especificidad de las carreras creativas. A nivel del segundo ciclo, el de las maestrías, encontramos que en aquellas que tienen un énfasis en la creación artística o en la interdisciplinariedad, las exégesis creativas ya tienen un lugar propio; pero, si estas maestrías son de corte más teórico los proyectos de investigación difícilmente salen del protocolo científico.

\section{FUENTES REFERENCIALES}

Asprilla, L. (2013). Los productos de la creación-investigación: la producción de conocimientos desde el arte. En Asamblea General de la Asociación Colombiana de Facultades y Programas de Artes- ACOFARTES (pp. 1-65). Cali: Instituto Departamental de Bellas Artes.

Bambula, J. (2014). Artes y conocimiento. Particularidades de la investigación/creación/producción en el campo estético. Revista a contratiempo, 29. Recuperado de http://www.musigrafia.org/acontratiempo/?ediciones/revista-23/artculos/artes-y-conocimientoparticularidades-de-la-investigacincreacinproduccin-en-el-campo-estetico.html

Borgdorff, H. (2006). El debate sobre la investigación en las artes. Recuperado de http://www.konst.gu.se/digitalAssets/1322/1322698 el-debate-sobre-la-investigaci--n-en-las-artes.doc

Colciencias. (2015). Modelo de medición de grupos de investigación, desarrollo tecnológico o innovación y de reconocimiento de investigadores del sistema nacional de ciencia, tecnología e innovación. Recuperado de http://www.colciencias.gov.co/sites/default/files/upload/noticias/mediciondegrupos-actene2015.pdf 
Silva Cañaveral, Sandra Johana; Herrera Zárate, Álvaro Ricardo.

La investigación en artes en Colombia: como la aprendimos, como la hacemos y como la enseñamos

IV Congreso INTERNACIONAL DE INVESTIGACIÓN EN ARTES VISUALES ANIAV 2019 IMAGEN [N] VISIBLE]

http://dx.doi.org/10.4995/ANIAV.2019.9173

Deleuze, G. y Guattari, F. (2004). Mil mesetas. Capitalismo y esquizofrenia. (Trad. José Vásquez Pérez). Valencia: Pre-textos. (Original en francés, 1988).

Grisales, A. (2012). ¿El artista como científico social?. En III Encuentro Latinoamericano de Metodología de las Ciencias Sociales celebrado en la Universidad de Caldas, Manizales, Colombia. (pp. 1-16). Manizales: Universidad de Caldas.

Hannula, M., Souranta, J., Vadén, T. (2005). Artistic Research - Theories, Methods and Practices. Finland: Academy of Fine Arts and University of Gothenburg.

Hannula, M., Souranta, J., Vadén, T. (2014). Artistic Research Methodology. Narrative, Power and the Public. New York: Peter Lang Publishing.

Hernández Hernández, F., Gómez Muntané, M., y Pérez López H. (2006). Bases para un debate sobre la investigación artística. Madrid: Ministerio de Educación y Ciencia.

Hernández Hernández, F. (2008). La investigación basada en las artes. Propuestas para repensar la investigación en la educación. Revista Educatio Siglo XXI, 26, 85-118. Recuperado de https://revistas.um.es/educatio/article/view/46641/44671

Michelkevicius, V. (2018). Mapping artistich research. Towards diagrammatic knowing. Lituania: Vilnus Academy af Arts Press.

Roldán, J., Marín, R. (2012). Metodologías artísticas de investigación en educación. Málaga: Aljibe.

Silva, S. (2016). La investigación-creación en el contexto de la formación doctoral en diseño y creación en Colombia. Revista de investigación, desarrollo e innovación, 7 (1), 49-61. https://doi.org/10.19053/20278306.v7.n1.2016.5601

Sousanis, N. (2015). Unflattening. Cambridge: Harvard University press.

Sullivan, G. (2005). Art practice as Research. Inquiry in the visual Arts. USA: Sage.

Tornero, P. (2013). Tecnologías de la creatividad: conexiones entre arte y ciencia en la contemporaneidad (Tesis doctoral). Universidad Complutense de Madrid, Madrid. 